\title{
Green Building Concept Application with VRF Air Conditioning System
}

DOI:10.36909/jer.ASSEEE.16107

\author{
Herman Soegoto \\ Departemen Manajemen, Universitas Komputer Indonesia
}

Email: hermansoegoto@email.unikom.ac.id

\begin{abstract}
The objective of this research is to find out the benefit of the Green Building Concept application with VRF Air Conditioning System at Indonesian Computer University. The research method used is descriptive quantitative analysis. Based on research findings, the VRF air conditioning system in Indonesian Computer University could reduce electrical power usage and the monthly cost for electrical power. However, the payback can only be reached after 15 years of operation. The other benefits are the space efficiency for more flexible placement of the outdoor unit and did not decrease the building's aesthetic appearance.
\end{abstract}

\section{INTRODUCTION}

The implementation of the construction concept that uses the green building concept continues to grow over time. The operation from a skyscraper construction usually requires immense electrical energy for lighting system in all rooms, air conditioning system, elevator, pumps, computer, printer, and other various devices.

The building owner, top manager, engineer, and building architect continuously think about designing a building that used electric energy as efficiently as possible. One of the solutions is by implementing the green architecture building concept. Green architecture is a modern architecture trend that is engineering the building harmonization and considering environmental aspects using renewable energy as the source, for example, the sunlight energy, air energy, water, or conventional technology that can decrease electricity consumption. The office building is considered a type of building that consumes a huge amount of energy compared to other 
building types (Radwan, M. R. et al., 2015). Green architecture is an approach to design a building that minimizes any harmful effects towards the health of people and environment, the architecture or designer try to protect the sustainability of the air, soil and water by choosing environmentally friendly material in their construction (Rettenwender, T. et al., 2009). Green building construction is one method that used resources wisely to build house and commercial buildings that have high quality, healthier, and more efficient energy utilization (Council, U. G. B. 2003). Green building is a product that can be marketed through various forms and features that are different from conventional buildings (Abuamer, E.et al., 2015). The building is the biggest energy user (62\%) and the main source of greenhouse gas emissions (55\%) (Anderson, J. E. et al., 2015). Energy-saving give a huge benefit to mitigate the high demand for energy through a green building concept (DeKay, M. et al., 2013). In a building, energy used for air conditioning is the most dominant (Chen, H. et al., 2015). Energy-saving due to air conditioning is the main concern when carrying a building project. One of the easiest and most efficient strategies to control the energy consumption from air conditioning is by implementing a temperature adjustment set point (Wang, N. et al., 2013). The higher the room temperature setting in the air conditioning system, the lower the consumption energy will be (Sunardi, C. et al., 2020).

This research aims to figure out how big electrical energy efficiency at Indonesian Computer University when using VRF Air Conditioning System in every office room, class, and laboratory. Hopefully, this could be an additional reference for companies or industries planning to use air conditioning installation in the office to help reduce the impact of greenhouse gas emissions and reduce the operating expenses used to pay for electricity.

\section{METHOD}

This research used a quantitative method by calculating how big the electrical energy efficiency used in Computer Indonesia University by utilizing the air conditioning VRF system. 
The analysis was also conducted by comparing the payback period from the initial investment side for the VRF system. The analysis uses several equations as follows:

- $\quad$ Total Cost $=$ electricity $\operatorname{cost} *$ kilowatt $*$ operating hour time

- $\quad$ Total Operating Cost Reducing $=$ Total cost of non-VRF System - Total cost with VRF System

- $\quad$ Payback period $=$ Total Operating Cost Reducing / Saving Cost each Year

\section{RESULTS AND DISCUSSION}

Variable Refrigerant Flow/Volume (VRF/VRV) system is one of the air conditioning technology that various air conditioning system producers develop to efficiently use electricity using the inverter technology. VRF system uses refrigerant R-410A that is environmentally friendly. VRF system enables the control of air conditioning supply in each room through automatic control and zoning system based on the operating cost/charge of/in each area.

Indonesian Computer University uses the green building concept in building design. For example, the university uses an automatic controllable exhaust fan operation system, open-air ventilation system, and the office and classroom use VRF air conditioning system for the three basement areas. VRF air conditioning system is used in each room in the university, and there are 12 floors in the university building, with 287 indoor and 24 outdoor VRF AC units. The total electrical power capacity installed is 653 horsepower or 487 kilowatts. The purpose of this VRF system implementation is for the efficiency of electrical power usage, buildings' aesthetic appearance both indoor and outdoor, and to promote an environmentally friendly campus. Apart from those, it is also because of the limited space availability; thus, VRF system outdoor unit placement in Indonesian Computer Indonesia is more likely to be placed in the building's roof and connect it with the indoor unit through piping refrigerant. 
The operating system uses the centralized remote control to control room temperature and manage the earliest and latest time. It can be operated in each room regarding the lecturer and staff working hours and the teaching time in the classroom. With this central system operation, the extravagance electricity usage outside the working hour could be prevented or when the staffs forget to turn off the air conditioning when they go home. Moreover, within the working hour, the air conditioning can be operated manually by the one who is in the room.

The price of air conditioning with a VRF system is usually 2 or 3 times higher than the split wall type. One outdoor unit can be used for several indoor units depends on the user's needs. Figure 1 is installation in Universitas Komputer Indonesia uses two outdoor units on each floor, and it is divided based on the zone, namely the north and south of the building. One outdoor unit consists of two or three compressors depend on the kilowatt load/consumption of the indoor unit.

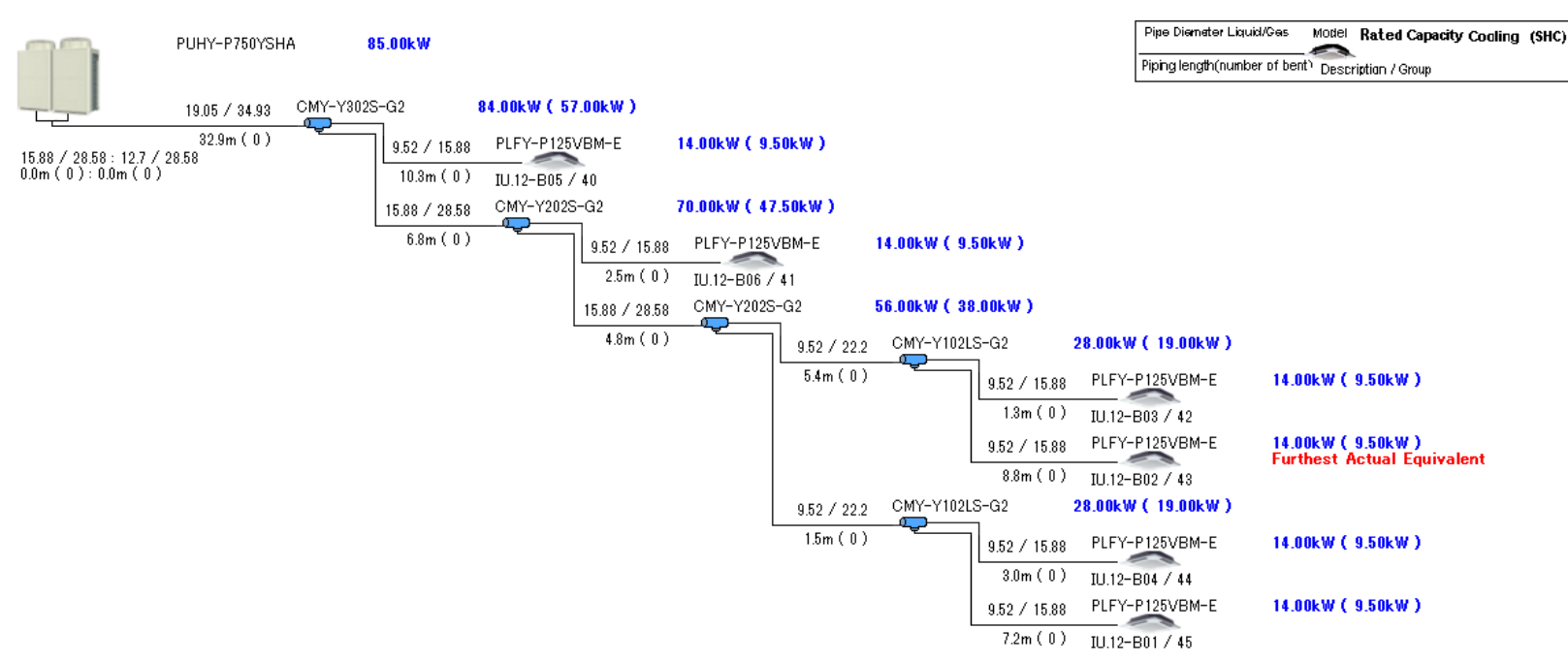

Figure 1. Piping and Instrument Diagram in Zone 2 of the 12th Floor

The operational hour on the campus is from 7 AM until 4 PM from Monday to Friday and 7 AM to 2 PM on Saturday. Meanwhile, the working hour for the lecturer is from 8 AM to 2 PM from Monday to Friday and 8 AM to 1 PM on Saturday. Electricity costs issued by the state's 
electricity company or known as PLN is Rp $1035.78 / \mathrm{kWh}$. The normal operating hour is calculated as one year minus two weeks of bank holidays, equal to 52 hours/week.

Total operating hour in one year $=52$ hours $\mathrm{x} 4$ weeks $\mathrm{x} 11.5$ months $=2392$ hours

The electricity cost in Indonesian Computer University according to the State Electricity Enterprise rules that are classified as Social Business S3K/865000 VA is 1036 Rupiah for each $\mathrm{kWh}$. Additionally, the installed air conditioning voltage is 487 kilowatt or $609 \mathrm{kVA}$.

Therefore, with an assumption of a normal working hour and when all the air conditioning system is operated based on the working hour using the AC and not VRF system, the total electricity expenses incur each month on average will be:

Total Cost $=\beta^{*} \mathrm{kw}^{*} \mathrm{t}^{*} \mathrm{~d}$

Total Cost $=$ Rp 1036 x 487 kw x 2392 hour $=$ Rp. 1.206 .840 .544 per year

On the other hand, when using air conditioning with a VRF system, a timer can set the operational hour. For example, in Figure 2. some part of the rooms, such as the lecture, dean, and faculty room that account for $50 \%$ of the total rooms, the AC operational in these rooms can be managed systematically where the AC starts to operate from 8 AM to 2 PM every day. Hence, the total operational hour with VRF system per year is:

Operational hour per week $=52$ hours $x 0,5+35$ hours $\times 0,5=26$ hours $+17,5$ hours $=43,5$ hours

Total Operational hour in one year $=43,5$ hours x 4 weeks x 11.5 months $=2001$ hours

Total Cost $=$ Rp $1036 \times 487$ kw x 2001 hours = Rp. 1.009.568.532 per year 


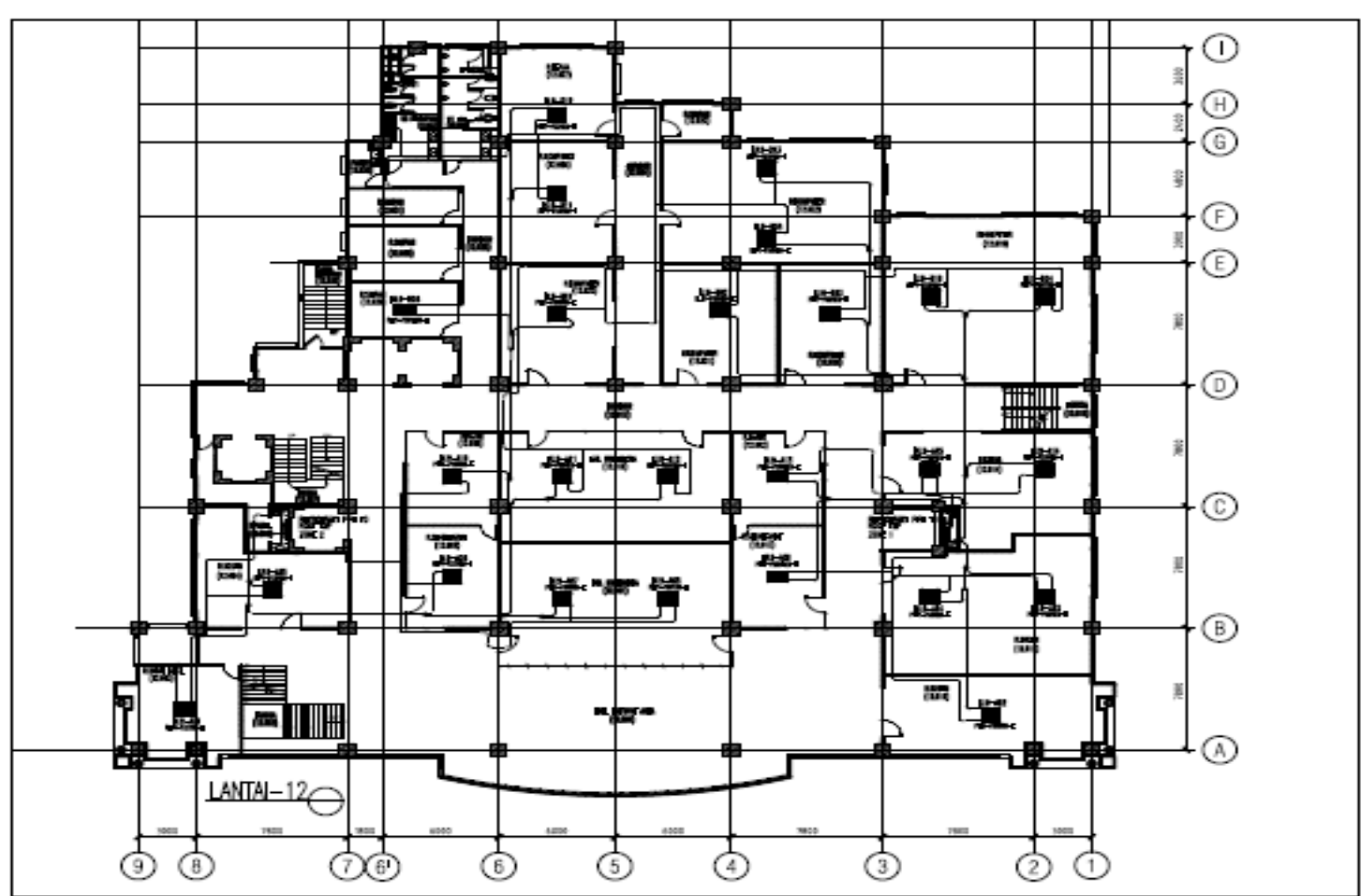

Figure 2. Indoor Unit Layout on the 12th Floor

Each floor is divided into two zones, indoor and outdoor units. For each outdoor unit of the VRF system, air conditioning is equipped with two inverter compressors. Thus if the total AC unit operated did not reach $50 \%$ of the capacity installed, there would only be one compressor that automatically operates. According to the observation on the field, approximately only $70 \%$ capacity of the classes, laboratories, and office room is used simultaneously, including the air conditioning operation. As a result, the prediction of total maximum cost is:

Total Cost $=$ Rp 1036 x 487 kw x 2001 hours x 0,7= Rp. 706.697 .972 per year

The cost saving in one year for VRF air conditioning system in comparison with the AC multi-split non VRF system is:

Savings $=$ Rp. 1.206.840.544 $-706.697 .972=$ Rp. 500.142 .572

Total energy saving $=($ Rp. 500.142.572 $/$ Rp. 1.206.840.544) $\times 100 \%=41,4 \%$.

The prediction calculation of total energy saving above is $41.4 \%$. The estimation is not that different from the research conducted by (Mageed, H. M. A. et al., 2017.), which concluded 
the total energy saving on a building that uses a Variable Refrigerant Flow is approximately $35 \%$ lower than the building with a non-inverter air conditioning system. Other research conducted by (Barros Alvarez, M. A. et al., 2015) stated that the potential saving is $30 \%$, and about $27.1 \%$ to $57.9 \%$ (Aynur, T. N. et al., 2009).

The purchasing cost AC VRF system is two times higher than non VRF system. If, for example, the total cost of all VRF systems is Rp. 15.000.000.000, there is a possibility that the total cost for non-VRF systems is approximately Rp. 7.500.000.000. Hence, the payback period for using air conditioning VRF system at Computer Indonesia University is:

Payback period $=$ addition cost for all AC unit / saving each year

Payback period $=$ Rp. 7.500.000.000 / Rp. 500.142.572 = 15 year

Currently, the air conditioning system has been operated for four years, and it still operates well without facing many issues. The lifetime of the VRF system is estimated to be between 10 to 15 years.

If referring to the shortest estimation lifetime of the VRF unit, which is ten years. Meanwhile, the payback is 15 years. Then it can be assumed that based on the investment value, investing in a VRF system is inefficient from the initial cost side to compare to the non-VRF system. The VRF system has higher cost implications than the mini-split system (Layeni, A. T. et al., 2019).

However, consider the limited space for outdoor unit placement in Indonesian Computer University, where it is only possible to put it on top of the building. The installation of the VRF system is still appropriate with the condition of Indonesian Computer University, especially in terms of the building aesthetic aspects, limited available space, and electrical energy efficiency. This electricity saving supports the concept of green building (It's shown in Figure 3. 


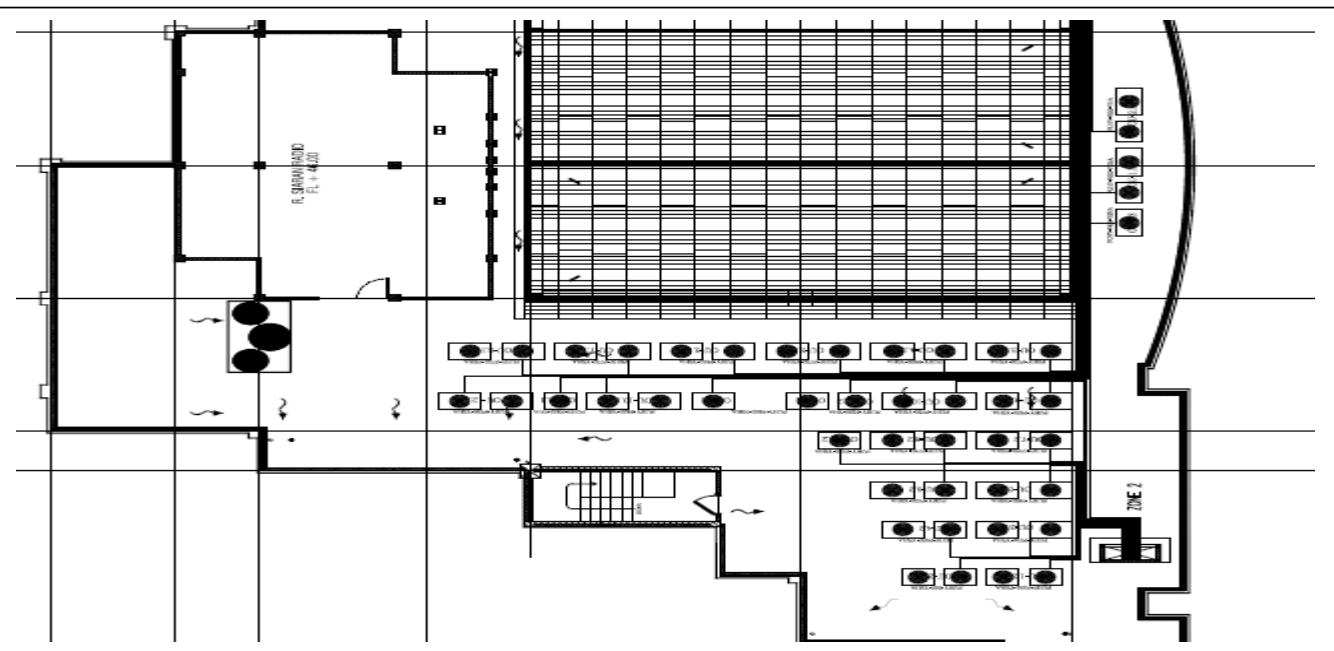

Figure 3. Outdoor Unit of VRF System Placement on the Roof Top of Building

\section{CONCLUSION}

The benefits perceived from utilizing the VRF air conditioning system at Indonesian Computer University could save electricity expenses up to $41 \%$ lower than the non-VRF system. However, due to the high investment cost, the payback period is possibly satisfied after 15 years of operating a VRF air conditioning system. Despite this, another benefit of the VRF system is the space efficiency to place the outdoor unit as it is more flexible and did not affect the building's aesthetic appearance.

\section{ACKNOWLEDGMENT}

We would like to thank Universitas Komputer Indonesia for supporting this journal. 


\section{REFERENCES}

Radwan, M. R., Kashyout, A. E. H. B., ELshimy, H. G., \& Ashour, S. F. 2015. Green building as concept of sustainability Sustainable strategy to design Office building. 2 nd ISCASE-2015 Dubai, 2: 41-80.

Rettenwender, T., \& Spitz, N. 2009. The Principles of Green Building Design. MA, Mag. Arch, MA, Mag. Arch., LEED AP, Architect and Niklas SpitzMonterey Peninsula College INTD62, Monterey Peninsula: 1-36

Council, U. G. B. 2003. LEED Reference Guide for New Construction \& Major Renovations (LEED-NC), Version 2.1. US Green Building Council.

Abuamer, E., \& Boolaky, M. 2015. Consumer Behavior towards Green Building: A Study in Abu Dhabi. International Journal of Business Administration, 6(3): 72-131.

Anderson, J. E., Wulfhorst, G., \& Lang, W. 2015. Energy analysis of the built environmentA review and outlook. Renewable and Sustainable Energy Reviews, 44: 149-158.

DeKay, M., \& Brown, G. Z. 2013. Sun, wind, and light: architectural design strategies. John Wiley \& Sons.

Chen, H., Lee, W. L., \& Wang, X. 2015. Energy assessment of office buildings in China using China building energy codes and LEED 2.2. Energy and buildings, 86: 514-524.

Wang, N., Zhang, J., \& Xia, X. 2013. Energy consumption of air conditioners at different temperature set points. Energy and Buildings, 65: 412-418.

Sunardi, C., Hikmat, Y. P., Margana, A. S., Sumeru, K., \& Sukri, M. F. B. 2020. Effect of room temperature set points on energy consumption in a residential air conditioning. In AIP Conference Proceedings, 2248(1), p. 070001.

Mageed, H. M. A., Omar, A. I., \& Aleem, S. H. A. 2017. Comparison of Traditional and Green Building Designs in Egypt: Energy Saving. International Journal of Energy and Environmental Engineering, 11(2): 244-247. 
Barros Alvarez, M. A., Balbis Morejon, M., Tovar Ospino, I., Castro Pena, J. J., De Leon

Siado, L. M., Silva Ortega, J. I., \& Rosales Villa, D. E. 2015. Comparación del consumo energético entre las tecnologías de aire acondicionado tipo mini-split y volumen de refrigerante variable en un edificio educativo: 1-9.

Aynur, T. N., Hwang, Y., \& Radermacher, R. 2009. Simulation comparison of VAV and VRF air conditioning systems in an existing building for the cooling season. Energy and Buildings, 41(11): 1143-1150.

Layeni, A. T., Nwaokocha, C. N., Giwa, S. O., Sulaiman, M. A., Adedeji, K. A., \& Olanrewaju, A. I. 2019. Design and Engineering Economic Analysis of a Variable Refrigerant Flow (VRF) and Mini-Split Air Conditioning System. Current Journal of Applied Science and Technology,34(1): 1-25. 